\title{
Facile synthesis of Curcuma longa tuber powder engineered metal nanoparticles for bioimaging applications
}

Renu Sankar ${ }^{\mathrm{a}}$, Pattanathu K. S. M. Rahman ${ }^{\mathrm{b}}$, Krishnamoorthy Varunkumar ${ }^{\mathrm{a}}$, Chidambaram Anusha ${ }^{a}$, Arunachalam Kalaiarasi ${ }^{a}$, Kanchi Subramanian Shivashangari ${ }^{{ }^{* * *}}$, Vilwanathan Ravikumar $^{\mathrm{a}^{*}}$

${ }^{a}$ Department of Biochemistry, School of Life Sciences, Bharathidasan University, Tiruchirappalli-620 024, Tamil Nadu, India.

${ }^{b}$ Technology Futures Institute, School of Science and Engineering, Teesside University, Middlesbrough - TS1 3BA, Tees Valley, UK.

${ }^{\mathrm{c}}$ Regional Forensic Science Laboratory, Tiruchirappalli, Tamil Nadu, India.

* Corresponding author at: Department of Biochemistry, School of Life Sciences, Bharathidasan University, Tiruchirappalli-620 024, Tamil Nadu, India. Tel.: +91 4312407071. Email: ravikumarbdu@gmail.com

** Corresponding author at: No-75, Second Street, Ashok Nagar, Kanchipuram-631 502, Tamil Nadu, India. Tel: +91 442 2726292. Email: shivashangari@gmail.com 


\begin{abstract}
Nanomaterials based fluorescent agents are rapidly becoming significant and promising transformative tools for improving medical diagnostics for extensive in vivo imaging modalities. Compared with conventional fluorescent agents, nano-fluorescence has capabilities to improve the in vivo detection and enriched targeting efficiencies. In our laboratory we synthesized fluorescent metal nanoparticles of silver, copper and iron using Curcuma longa tuber powder by simple reduction. The physicochemical properties of the synthesized metal nanoparticles were attained using UV-visible spectrophotometry, scanning electron microscopy with EDAX spectroscopy, dynamic light scattering, Fourier-transform infrared spectroscopy and X-ray diffraction. The Curcuma longa tuber powder has one of the bioactive compound Curcumin might act as a capping agent during the synthesis of nanoparticles. The synthesized metal nanoparticles fluorescence property was confirmed by spectrofluorometry. When compared with copper and iron nanoparticles the silver nanoparticles showed high fluorescence intensity under spectrofluorometry. Moreover, in vitro cell images of the silver nanoparticles in A549 cell lines also correlated with the results of spectrofluorometry. These silver nanoparticles show inspiring cell-imaging applications. They enter into cells without any further modifications, and the fluorescence property can be utilized for fluorescence-based cell imaging applications.
\end{abstract}

Keywords: Curcuma longa; fluorescent nanoparticles; spectrofluorometry; biocompatibility; A549 cells; cell-imaging. 


\section{Introduction}

Recent bioimaging techniques have providing substantial platform for disease diagnosis and therapy. Since most of the diseases happen at cellular level, researchers face problems associated with viewing and understanding these processes exactly and in real time [1]. Nanotechnology shows a preeminent role in all aspects of science and technology owing to the exclusive properties of nanoscale materials [2]. The newest developments in nanotechnology have led to extensive growth in the creation of different nanosized materials which includes wires, fibers, tubes and particles for multiplicity biomedical applications [3]. Nanoscience and nanotechnology are providing new approaches to tailored materials with enhanced applications such as targeted gene delivery, diagnostic devices, sensor and molecular level therapeutic approaches [4]. Fluorescent nanomaterials have recently been developed, offer plenty of opportunities in biomedical field [5]. The fluorescent nanomaterials are primarily used in imaging, disease diagnosis and understanding cellular level biological process. However, by reason of their toxic nature the usage is very limited $[6,7]$, therefore we are in the need for developing less toxic fluorescent nanomaterials. On account of small size, diverse shape and high surface to volume ratio, the metal nanoparticles have typical physicochemical, optical, electrical and biological properties [8]. Moreover, the metal nanoparticles exhibit surface plasmon resonance (SPR) and surface enhanced Raman scattering (SERS) effect [9].

The metal nanoparticles can be synthesized through various methods (Physical and chemical), and their synthesis using highly efficient biological methods is finding applications in the medicinal field [10]. When compared to other methods the biological way is not only environmental friendly, inexpensive and non-hazardous, but also for it can be used to synthesize large volumes of precisely sized and shaped nanomaterials [11]. Moreover, we have recently 
reported that the medicinal plant aqueous leaf extract mediated silver, copper oxide and titanium dioxide nanoparticles exhibit antimicrobial, anticancer, photocatalytic, and wound healing activity [12-14].

Curcuma longa (C. longa), normally called turmeric, is derived from rhizomes of the plant and has a long history of use in Indian Ayurvedic medicine [15]. Curcumin (1,7-bis (4hydroxy-3-methoxyphenyl)-1,6-heptadiene-3,5-dione) is one of the major principal coloring bioactive compound present in the C. longa tuber powder and has extensive biological activity including anti-inflammatory, anti-oxidant, anti-carcinogenic, anti-ageing and anti-mutagenic effects [16]. Curcumin, a fluorescent molecule with emission properties highly dependent on the polarity of its environment, has been extensively considered for its photophysical and fluorescent enhancement properties [17].

Generally fluorescent nanomaterials are synthesis by high energy ion beam radiation, laser ablation and electrooxidation methods [18]. These all have drawbacks in biomedical applications. The currently accessible fluorescence probes like organic dyes, fluorescent inorganic/organic nanoparticles and fluorescent proteins have inherent disadvantages such as reduced membrane permeability and susceptibility to photo-bleaching [19]. Probable toxic owing to their accumulation in the reticuloendothelial system the well characterized fluorescent quantum dots, carbon dots, silicon quantum dots and metal clusters usage also restricted in bioimaging field [20]. Therefore, synthesis of novel fluorescent materials with good biocompatibility, high fluorescence and low toxicity is still urgently required. In this paper, we demonstrate a simple one step environmental friendly synthesis of fluorescent metal nanoparticles using C. longa tuber powder. 


\section{Materials and methods}

\subsection{Extraction preparation}

The $C$. longa tubers were collected from the local market and washed thoroughly, air dried for two weeks to remove the moisture content, powdered in a mixer grinder, and sieved to a uniform size. The resulting turmeric powder was used in the present study.

\subsection{Green synthesis of silver, copper and iron nanoparticles}

Turmeric was suspended in $100 \mathrm{ml}$ of deionized water in an Erlenmeyer flask and stirred for $5 \mathrm{~h}$ at room temperature. Silver nanoparticles were prepared by adding $5 \mathrm{mM}$ silver nitrate $\left(\mathrm{AgNO}_{3}\right)$ solution in to the turmeric suspension followed by stirring for $24 \mathrm{~h}$ at room temperature. The resulting dark-brown colored silver nanoparticles were centrifuged at 12,000 rpm for 20 minutes and washed four to five times with deionized water. A similar procedure was used to synthesize copper and iron nanoparticles using $5 \mathrm{mM}$ cupric sulphate $\left(\mathrm{CuSO}_{4} \cdot 5 \mathrm{H}_{2} \mathrm{O}\right)$ and $5 \mathrm{mM}$ iron (III) chloride hexahydrate $\left(\mathrm{FeCl}_{3} \cdot 6 \mathrm{H}_{2} \mathrm{O}\right)$ solution respectively.

\subsection{Characterization of metal nanoparticles}

The turmeric-mediated metal nanoparticles were confirmed by UV-visible double beam spectrophotometer (UV-1601, Shimadzu, Japan), operating at 300-700 nm. The size and zeta potential distribution were attained by Malvern Zetazier (Nano ZS90, UK) instrument. The morphology and elemental composition of the synthesized metal nanoparticles were established by scanning electron microscopy (SEM) with energy-dispersive X-ray spectroscopy (EDAX) (VEGA3 TESCAN, 30.0 KV). Fourier transform infrared spectroscopy (FT-IR) was achieved by 
spectrum RX- 1 instrument in diffuse reflectance mode operated at a resolution of $4 \mathrm{~cm}^{-1}$, range of 4000-400 $\mathrm{cm}^{-1}$. X-ray diffraction (XRD) patterns were obtained using a powder X-ray diffractometer (Philips X'Pert Pro X-ray diffractometer) in $2 \theta$ range from $10^{\circ}$ to $80^{\circ}$.

\subsection{Hemolysis assay}

The biocompatibility of green synthesized metal nanoparticles can be confirmed by hemolysis assay. Red blood cells (RBCs) were separated by centrifuging blood drawn from mice (Swiss albino) in phosphate buffered saline (PBS) solution at $1000 \mathrm{rpm}$ for $10 \mathrm{~min}$. The detached pellet was washed and re-suspended in $2 \mathrm{~mL}$ of PBS solution. For the hemolysis assay, $100 \mu \mathrm{L}$ of diluted RBCs were treated with silver, copper and iron nanoparticles $(2 \mu \mathrm{g} / \mathrm{mL}) .100 \mu \mathrm{L}$ of diluted RBCs treated with $500 \mu \mathrm{L}$ of distilled water and $500 \mu \mathrm{L}$ of PBS assisted as a positive and negative controls respectively. The samples were incubated for $1 \mathrm{~h}$ at $37^{\circ} \mathrm{C}$ followed by centrifugation at15, 000 for $10 \mathrm{~min}$. The separated supernatant was analyzed at $575 \mathrm{~nm}$ using an Elisa reader and the percentage of hemolysis was calculated as follows:

$$
\text { Percentage of hemolysis }=\frac{\text { sample absorbance }- \text { negative control }}{\text { positive control }- \text { negative control }} \times 100
$$

\subsection{Fluorescence spectra}

Emission spectra of turmeric-mediated metal nanoparticles $(100 \mu \mathrm{g} / 2 \mathrm{~mL}$ of distilled water) were obtained using a Perkin Elmer-LS55 spectrofluorometer operating at an excitation wavelength range of 400-700 $\mathrm{nm}$. 


\subsection{Cell culture}

The human non-small cell lung cancer A549 cells were obtained from the National Center for Cell Science, Pune, India. They were cultured in Dulbecco's modified Eagle's medium supplemented with $10 \%$ fetal bovine serum and $1 \%$ penicillin/streptomycin.

\subsection{In-vitro cellular imaging}

For cellular imaging, $5 \times 10^{5}$ cells were seeded on a cover slip in 6-well plate and incubated overnight for attachment. After successful attachment the cells were treated with fresh medium containing metal nanoparticles such as silver, copper and iron nanoparticles, and incubated for $6 \mathrm{~h}$. At the end of incubation the cover-slip was washed with PBS solution and cell images were captured using $20 \times$ objectives (Blue, red and green filter) under fluorescence microscope.

\section{Results and discussion}

\subsection{Mechanism of fluorescence metal nanoparticles formation}

Much research has demonstrated that $C$. longa tuber powder has natural fluorescence due to the presence of curcumin, some studies have been carried out to investigate the interaction between metals and curcumin [21-23] to show that the curcumin keto and enol group oxygen lone pairs interact with acceptor orbital of metal ions, and may act as a strong reducing, encapsulating and stabilizing agent for the formation of fluorescent metal nanoparticles (Fig. 1). In the present study, we explore the formation of fluorescent metal nanoparticles under the influence of turmeric. 


\subsection{Synthesis of fluorescence metal nanoparticles}

The metal nanoparticles were synthesized by simple reduction turmeric [24]. The $C$. longa tuber powder was originally yellow in color (Supplementary Fig. 1(a)), upon reaction with nanoparticle precursor solutions of $\mathrm{AgNO}_{3}, \mathrm{CuSO}_{4} \cdot 5 \mathrm{H}_{2} \mathrm{O}$, and $\mathrm{FeCl}_{3} \cdot 6 \mathrm{H}_{2} \mathrm{O}$ it formed respectively brown color nanoparticles (Supplementary Fig. 1(b, c, d)). This might be due to the excitation of surface plasmon vibrations in the nanoparticles [25]. The reduction of silver, copper and iron ions were subjected to analysis through the UV-Vis spectrophotometer. The C. longa tuber powder did not show any correspondence absorbance peak under UV- Vis spectra (Fig. 2(a)), whereas the C. longa tuber powder mediated silver, copper and iron nanoparticles in the colloidal solution shows absorbance peak at $440 \mathrm{~nm}, 235 \mathrm{~nm}$ and $250 \mathrm{~nm}$ (Fig. 2(b, c, d)), respectively. The frequency and width of the surface plasmon absorption predominantly depends on the size and shape of the metal nanoparticles [26].

\subsection{Characterization of fluorescence metal nanoparticles}

Dynamic light scattering (DLS) analysis is mainly used to find out the size and surface charge of the nanomaterials, and indirectly expresses stability of the nanoparticles [14]. The DLS analysis shows turmeric mediated silver, copper and iron nanoparticles mean particle size to be $102 \mathrm{~nm}, 190 \mathrm{~nm}$ and $215 \mathrm{~nm}$ (Fig. 3(a, b, c)), respectively. Zeta potential distribution displayed a negative potential of about $-35 \mathrm{mV},-26.7 \mathrm{mV}$ and $-15.5 \mathrm{mV}$ respectively (Fig. 4(a, b, c)). From the Zeta potential distribution results, it is clear that the higher negative charge of silver nanoparticles compared with other nanoparticles might be due to the high concentration of bioactive compounds capped in the silver nanoparticles surface. Among the three green synthesized metal nanoparticles, silver nanoparticles showed lowest particle size distribution, 
and the particles had high stability in the colloidal solution. It has been reported that the size and surface charge plays a main role in regulating biological efficiency of the synthesized nanoparticles which also helps to prevent agglomeration [12, 27].

SEM results, presented in Fig. 5(a, b, c) demonstrated that the synthesized silver, copper and iron nanoparticles are spherical in shape and evenly distributed throughout the colloidal solution. When compared with silver nanoparticles the copper and iron nanoparticles show some agglomeration. The EDAX analysis is a promising tool for understanding the elemental composition of the synthesized metal nanoparticles. As shown in Supplementary Fig. 2(a, b, c) silver, copper and iron nanoparticles exhibit strong elemental peak of silver, copper and iron respectively.

In the present study, FT-IR was used to confirm the role of bioactive components present in C. longa tuber powder in the metal nanoparticles formation [13]. Previous findings demonstrated that pure curcumin shows FTIR peaks at $3595 \mathrm{~cm}^{-1}, 3075 \mathrm{~cm}^{-1}, 1600 \mathrm{~cm}^{-1}, 1510$ $\mathrm{cm}^{-1}, 1425 \mathrm{~cm}^{-1}, 1280 \mathrm{~cm}^{-1}$ [28]. In our FTIR analysis silver, copper and iron nanoparticles exhibited similar peaks (Fig. 6(b, c, d)) which correlate well with the FTIR spectrum of C. longa tuber powder (Fig. 6(a)). The FTIR spectral peaks reveals the occurrence of bands relevant to amide O-H stretching $\left(3214 \mathrm{~cm}^{-1}\right)$, ether C-O stretching $\left(1397 \mathrm{~cm}^{-} 1,1128 \mathrm{~cm}^{-1}\right)$ and aromatic C$\mathrm{H}$ bending $\left(831 \mathrm{~cm}^{-1}\right)$. Low frequency of the band at $1569 \mathrm{~cm}^{-1}$ in the metal nanoparticles relative to the classic $\mathrm{C}=\mathrm{O}$ stretch is due to the extensive conjugation in curcumin, and the spectrum is good agreement with that of curcumin capping. The change in symmetry of the band at about $1600 \mathrm{~cm}^{-1}$ and perhaps the appearance of a low frequency shoulder on the band at about $1000 \mathrm{~cm}^{-1}$ confirmed curcumin capped in the metal nanoparticles surface. FTIR results clearly confirmed the tuber powder having bioactive compounds particularly curcumin might performed 
its role as reducing and capping agent in the metal nanoparticles formation. The FTIR spectra of C. longa and nanoparticles are almost superimposable, therefore we confirmed that the $C$. longa tuber powder mignt be act as reducing and capping agent in the metal nanoparticles formation.

The XRD can be used to confirm the crystalline nature and face-centred cubic (fcc) structure of synthesized metal nanoparticles. The XRD analysis revealed distinct diffraction peaks at $17.261^{\circ}, 38.093^{\circ}, 44.047^{\circ}, 64.492^{\circ}$ and $77.208^{\circ}$ that indexed the planes (002), (111), (200), (220) and (311) of fcc structure of silver (Fig. 7(a)). The XRD patterns noticeably disclose the green synthesized silver nanoparticles are crystalline in nature (Fig. 7(a)). Copper and Iron nanoparticles lack XRD distinct diffraction peaks, specified that the nanoparticles are amorphous in nature $($ Fig. $7(\mathrm{~b}, \mathrm{c}))$. Njagi et al reported that the plant extract mediated some metal nanoparticles are amorphous in nature [29].

\subsection{Hemolysis assay}

If nanomaterials are to be used for imaging, they should be biocompatible and hence suitable for its in vivo biological applications. The hemolysis assay is a well-accepted method to confirm the biocompatibility [30]. The green synthesized silver, copper and iron nanoparticles were evaluated for biocompatibility in mice RBCs. The hemolysis assay result displays less than $1 \%$ of hemolysis happened in metal nanoparticles treated group which is very much near to negative control (PBS), whereas positive control (water) treated group shows $100 \%$ hemolysis (Supplementary Fig. 3). According to ISO/TR 7406 the critical safe bio materials hemolytic ratio should be below 5\% [31]. An enormous recent research report showed green synthesized metal nanoparticles were biocompatible under optimum concentration [32]. Our hemolysis results 
indicate that the turmeric-mediated fluorescent metal nanoparticles have good hemolytic biocompatible and therefore may be suitable agents for in vivo imaging purposes.

\subsection{Fluorescence assay and in vitro cellular imaging}

The fluorescence emission of $C$. longa tuber powder and metal nanoparticles were confirmed using spectrofluorometry. As shown in Supplementary Fig. 4, C. longa tuber powder including green synthesized metal nanoparticles shows emission spectra at $535 \mathrm{~nm}$ [33]. When compared with metal nanoparticles, $C$. longa tuber powder emitted maximum intensity under spectrofluorometry due to the presence of curcumin (Supplementary Fig. 4(a)). The metal nanoparticles reduced fluorescence intensity when compared with C. longa tuber powder due to the quenching effect of nanoparticles. Among the three different metal nanoparticles, silver nanoparticles emitted high fluorescence, copper nanoparticles shows reduced fluorescence intensity and iron nanoparticles displays very less fluorescence emission at $535 \mathrm{~nm}$ under spectrofluorometry (Supplementary Fig. 4(b, c, d)). The spectrofluorometry results strongly indicate that the curcumin present in the turmeric has capped in the metal nanoparticles.

To investigate the utility of the metal nanoparticles as tools for imaging applications, we have performed in vitro cellular imaging experiments in human lung cancer A549 cells [34]. The A549 cells were treated with turmeric-mediated metal nanoparticles for $6 \mathrm{~h}$ and then examined by fluorescence microscopy. The analysis results show that the metal nanoparticles are actively take up by the A549 cancer cells, and emitted fluorescence under fluorescence microscope, while the control cells was colorless where no metal nanoparticles was used (Fig. 8(a, b, c, d)). This result confirms that metal nanoparticles can able to penetrate in A549 cells, and can be certainly detected using fluorescence microscope [35]. Moreover, in vitro cell image of the silver 
nanoparticles in A549 cells are well interconnected with our results of spectrofluorometry. Based on previous reports and our present findings we are sure that, the C. longa tuber powder mediated silver nanoparticles are nontoxic and can be used for biological applications [36, 37]. The $C$. longa tuber powder mediated high fluorescent natured silver nanoparticles are potentially a useful tool for imaging and biomedical applications. 


\section{Conclusion}

In this work, fluorescent natured metal nanoparticles were successfully synthesized using $C$.

longa tuber powder. The $C$. longa tuber powder have bioactive compounds performed the role of reducing agent for formation of the nanoparticles and subsequently caps the particles to impart fluorescence. Among different metal nanoparticles, the silver nanoparticles showed smaller monodispersed particles, and high Zeta potential distribution in the colloidal solution. Moreover, silver nanoparticles displayed face-centred cubic structure with crystalline in nature. Furthermore, spectrofluorometry and fluorescence microscopy studies showed silver nanoparticles was emitted high fluorescence and is actively take up by the A549 lung cancer cells. The cost effective, ecofriendly and high fluorescent natured silver nanoparticles can be incorporated as an innovative agent for biomedical applications specially in cancer theragnosis. 


\section{Acknowledgements}

We are grateful to Department of Science and Technology (DST) for providing financial assistance to Mr. Renu Sankar through INSPIRE Fellowship scheme [Grant no. DST/INSPIRE Fellowship/2010/229C]. We acknowledge the Department of Science and Technology-Fund for Improvement of S \& T Infrastructure in Universities and Higher Educational Institutions (DST-FIST) for their financial support to promote the infrastructure facility of our department

[Grant no. SR/FST/LSI-075/2011 dated.20.12.2011]. The authors are grateful to Dr. A. Antony Joseph Velanganni, Department of Biochemistry, Bharathidasan University, Tiruchirappalli for his help with fluorescence studies. We also thank Dr. M.V. Rao, School of Life Sciences, Bharathidasan University, Tiruchirappalli for his help in spectrofluorometry studies. We also thankful to Dr. Christopher J. Ennis for his critical comments on FTIR data analysis. 


\section{References}

[1] N. Erathodiyil, J.Y. Ying, Functionalization of inorganic nanoparticles for bioimaging applications, Acc Chem Res. 44 (2011) 925-935.

[2] R. Sankar, R. Maheswari, S. Karthik, K.S. Shivashangari, V. Ravikumar, Anticancer activity of Ficus religiosa engineered copper oxide nanoparticles, Mater Sci Eng C Mater Biol Appl. 44 (2014) 234-239.

[3] M. Longmire, P.L. Choyke, H. Kobayashi, Clearance properties of nano-sized particles and molecules as imaging agents: considerations and caveats, Nanomedicine (Lond) 3 (2008) 703717.

[4] D. Rueda, N.G. Walter, Single molecule fluorescence control for nanotechnology, J Nanosci Nanotechnol. 5 (2005) 1990-2000.

[5] Y. Xia, Nanomaterials at work in biomedical research, Nat Mater. 7 (2008) 758-760.

[6] Y. Min, J. Li, F. Liu, P. Padmanabhan, E.K.L. Yeow, B. Xing, Recent advance of biological molecular imaging based on lanthanide-doped upconversion-luminescent nanomaterials, Nanomaterials 4 (2014) 129-154.

[7] J.T. Kwon, S.K. Hwang, H. Jin, D.S. Kim, A. Minai-Tehrani, H.J. Yoon, M. Choi, T.J. Yoon, D.Y. Han, Y.W. Kang, B.I. Yoon, J.K. Lee, M.H. Cho, Body distribution of inhaled fluorescent magnetic nanoparticles in the mice, J Occup Health. 50 (2008) 1-6.

[8] M.C. Daniel, D. Astruc, Gold nanoparticles: assembly, supramolecular chemistry, quantumsize-related properties, and applications toward biology, catalysis, and nanotechnology, Chem Rev. 104 (2004) 293-346. 
[9] K.B. Narayanan, N. Sakthivel, Green synthesis of biogenic metal nanoparticles by terrestrial and aquatic phototrophic and heterotrophic eukaryotes and biocompatible agents, Adv Colloid Interface Sci. 169 (2011) 59-79.

[10] A.K. Mittal, Y. Chisti, U.C. Banerjee, Synthesis of metallic nanoparticles using plant extracts, Biotechnol Adv. 31 (2013) 346-356.

[11] J.E. Hutchison, Greener nanoscience: a proactive approach to advancing applications and reducing implications of nanotechnology, ACS Nano 2 (2008) 395-402.

[12] R. Sankar, A. Karthik, A. Prabu, S. Karthik, K.S. Shivashangari, V. Ravikumar, Origanum vulgare mediated biosynthesis of silver nanoparticles for its antibacterial and anticancer activity, Colloids Surf. B. 108 (2013) 80-84.

[13] R. Sankar, P. Manikandan, V. Malarvizhi, T. Fathima, K.S. Shivashangari, V. Ravikumar, Green synthesis of colloidal copper oxide nanoparticles using Carica papaya and its application in photocatalytic dye degradation, Spectrochim Acta A Mol Biomol Spectrosc. 121 (2014) 746750.

[14] R. Sankar, R. Dhivya, K.S. Shivashangari, V. Ravikumar, Wound healing activity of Origanum vulgare engineered titanium dioxide nanoparticles in Wistar Albino rats, J Mater Sci Mater Med. 25 (2014) 1701-1708.

[15] J.S. Jurenka, Anti-inflammatory properties of curcumin, a major constituent of Curcuma longa: a review of preclinical and clinical research, Altern Med Rev. 14 (2009) 141-153.

[16] C.S. Beevers, S. Huang, Pharmacological and clinical properties of curcumin, Botanics: Targets and Therapy. 1 (2011) 5.

[17] C.F. Chignell, P. Bilski, K.J. Reszka, A.G. Motten, R.H. Sik, T.A. Dahl, Spectral and photochemical properties of curcumin, Photochem. Photobiol. 59 (1994) 295-302. 
[18] R.K. Jha, P.K. Jha, K. Chaudhury, S.V. Rana, S.K. Guha, An emerging interface between life science and nanotechnology: present status and prospects of reproductive healthcare aided by nano-biotechnology, Nano Rev. 5 (2014) doi:10.3402/nano.v5.22762.

[19] X. Zhang, X. Zhang, L. Tao, Z. Chi, J. Xu, Y. Wei, Aggregation induced emission-based fluorescent nanoparticles: fabrication methodologies and biomedical applications, J. Mater.

Chem. B. 2 (2014) 4398-4414.

[20] X. Zhang, S. Wang, L. Xu, L. Feng, Y. Ji, L. Tao, S. Li, Y. Wei, Biocompatible polydopamine fluorescent organic nanoparticles: facile preparation and cell imaging, Nanoscale 4 (2012) 5581-5584.

[21] M. Asti, E. Ferrari, S. Croci, G. Atti, S. Rubagotti, M. Iori, P. C. Capponi, A. Zerbini, M. Saladini, A. Versari, Synthesis and characterization of (68)Ga-labeled curcumin and curcuminoid complexes as potential radiotracers for imaging of cancer and Alzheimer's disease, Inorg Chem. 53 (2014) 4922-4933.

[22] L. Baum, A. Ng, Curcumin interaction with copper and iron suggests one possible mechanism of action in Alzheimer's disease animal models, J Alzheimers Dis. 6 (2004) 367-377. [23] X.Z. Zhao, T. Jiang, L. Wang, H. Yang, S. Zhang, P. Zhou, Interaction of curcumin with $\mathrm{Zn}(\mathrm{II})$ and $\mathrm{Cu}(\mathrm{II})$ ions based on experiment and theoretical calculation, J Mol Struct. 984 (2010) 316-325.

[24] K. Shameli, M.B. Ahmad, A. Zamanian, P. Sangpour, P. Shabanzadeh Y. Abdollahi, M. Zargar, Green biosynthesis of silver nanoparticles using Curcuma longa tuber powder, Int J Nanomedicine. 7 (2012) 5603-5610. 
[25] C. Krishnaraj, E.G. Jagan, S. Rajasekar, P. Selvankumar, P.T. Kalaichelvan, N. Mohan, Synthesis of silver nanoparticles using Acalypha indica leaf extracts and its antibacterial activity against water borne pathogens, Colloids Surf. B. 76 (2010) 50.

[26] P. Mukherjee, A. Ahmad, D. Mandal, S. Senapati, S.R. Sainkar, M.I. Khan, R. Parishcha, P.V. Ajaykumar, M. Alam, R. Kumar, M. Sastry, Fungus-mediated synthesis of silver nanoparticles and their immobilization in the mycelial matrix: A novel biological approach to nanoparticle synthesis, Nano Lett. 1 (2001) 515-519.

[27] S.M. Moghimi, A.C. Hunter, J.C. Murray, Nanomedicine: current status and future prospects, FASEB J. 19 (2005) 311-330.

[28] V.R. Yadav, S. Suresh, K. Devi, S. Yadav, Effect of cyclodextrin complexation of curcumin on its solubility and antiangiogenic and anti-inflammatory activity in rat colitis model, AAPS Pharm Sci Tech. 10 (2009) 752.

[29] E.C. Njagi, H. Huang, L. Stafford, H. Genuino, H.M. Galindo, J.B. Collins, G.E. Hoag, S.L. Suib, Biosynthesis of iron and silver nanoparticles at room temperature using aqueous sorghum bran extracts, Langmuir 27 (2011) 264-271.

[30] A. Mayer, M. Vadon, B. Rinner, A. Novak, R. Wintersteiger, E. Fröhlich, The role of nanoparticle size in hemocompatibility, Toxicology 258 (2009) 139-147.

[31] N.S. Rejinold, M. Muthunarayanan, V.V. Divyarani, P.R. Sreerekha, K.P. Chennazhi, S.V. Nair, H. Tamura, R. Jayakumar, Curcumin-loaded biocompatible thermoresponsive polymeric nanoparticles for cancer drug delivery, J Colloid Interface Sci. 360 (2011) 39-51. [32] S. Gurunathan, J. Han, J.H. Park, J.H. Kim, A green chemistry approach for synthesizing biocompatible gold nanoparticles, Nanoscale Res Lett. 9 (2014) 248. 
[33] A. Altunbas, S.J. Lee, S.A. Rajasekaran, J.P. Schneider, D.J. Pochan, Encapsulation of curcumin in self-assembling peptide hydrogels as injectable drug delivery vehicles, Biomaterials 32 (2011) 5906-5914.

[34] Y. Urano, D. Asanuma, Y. Hama, Y. Koyama, T. Barrett, M. Kamiya, T. Nagano, T. Watanabe, A. Hasegawa, P.L. Choyke, H. Kobayashi, Selective molecular imaging of viable cancer cells with pH-activatable fluorescence probes, Nat Med.15 (2009) 104-109.

[35] J. Wang, G. Zhang, Q. Li, H. Jiang, C. Liu, C. Amatore, X. Wang, In vivo self-bio-imaging of tumors through in situ biosynthesized fluorescent gold nanoclusters, Sci Rep. 3 (2013) 1157. [36] J. Pan, J. Wei, J. Shen, S. Guo, Y. Sheng, X. Zhang, B. Feng, Green synthesis of surface plasmons photoluminescence enhancement $\mathrm{ZnSe} / \mathrm{Au}$ nanocomposites and its bioimaging application, Phys. D: Appl. Phys. 47 (2014) 045504.

[37] S.K. Bhunia, A. Saha, A.R. Maity, S.C. Ray, N. R. Jana, Carbon nanoparticle-based fluorescent bioimaging probes, Sci Rep. 3 (2013) 1473. 


\section{Figure captions}

Fig. 1. Schematic illustration of Curcuma longa tuber powder has curcumin capped in the metal nanoparticles

Fig. 2. UV-Vis absorbance spectra of (a) Curcuma longa tuber powder; (b) Silver nanoparticles;

(c) Copper nanoparticles; (d) Iron nanoparticles

Fig. 3. Particle size distribution of (a) Silver nanoparticles; (b) Copper nanoparticles; (c) Iron nanoparticles

Fig. 4. Zeta potential measurement of (a) Silver nanoparticles; (b) Copper nanoparticles; (c) Iron nanoparticles

Fig. 5. Scanning electron microscopic analysis of (a) Silver nanoparticles; (b) Copper nanoparticles; (c) Iron nanoparticles

Fig.6. FTIR spectrum of (a) Curcuma longa tuber powder; (b) Silver nanoparticles; (c) Copper nanoparticles; (d) Iron nanoparticles

Fig. 7. XRD pattern of (a) Silver nanoparticles; (b) Copper nanoparticles; (c) Iron nanoparticles

Fig. 8. Fluorescence microscopic images of human A549 non-small cell lung cancer cells after 6 $\mathrm{h}$ incubated with metal nanoparticles. 


\section{Supplementary figure captions}

Fig. 1. Color changes (a) Curcuma longa tuber powder; (b) Silver nanoparticles; (c) Copper nanoparticles; (d) Iron nanoparticles

Fig. 2. EDAX spectrum of (a) Silver nanoparticles; (b) Copper nanoparticles; (c) Iron nanoparticles

Fig. 3. Hemolysis assay of metal nanoparticles incubated on red blood cells. (Water- Positive control; PBS-Negative control; Ag-Silver nanoparticles; Cu- Copper nanoparticles; Fe- Iron nanoparticles)

Fig. 4. Fluorescence emission spectra of (a) Curcuma longa tuber powder; (b) Silver nanoparticles; (c) Copper nanoparticles; (d) Iron nanoparticles 
Fig. 1.

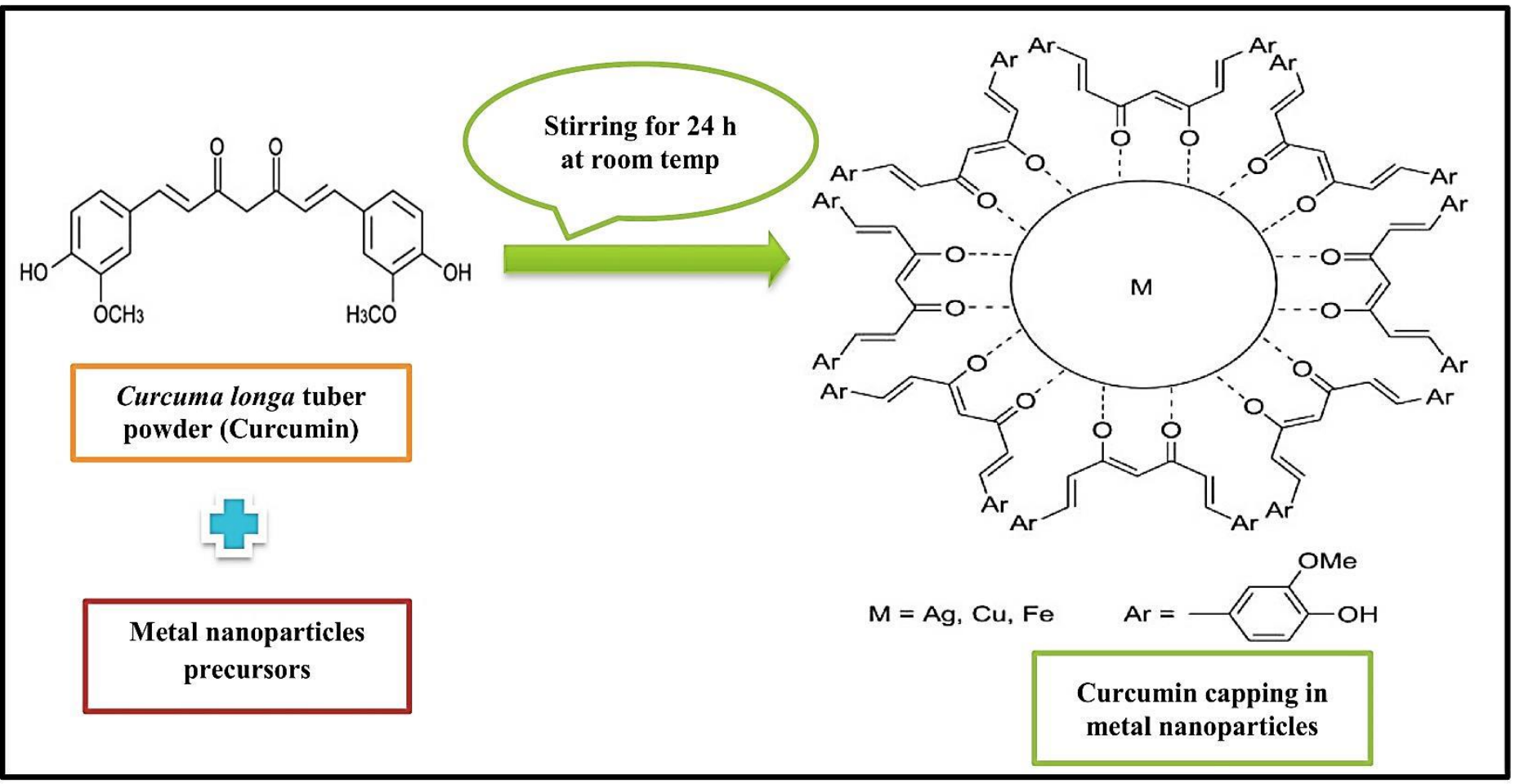


Fig. 2.

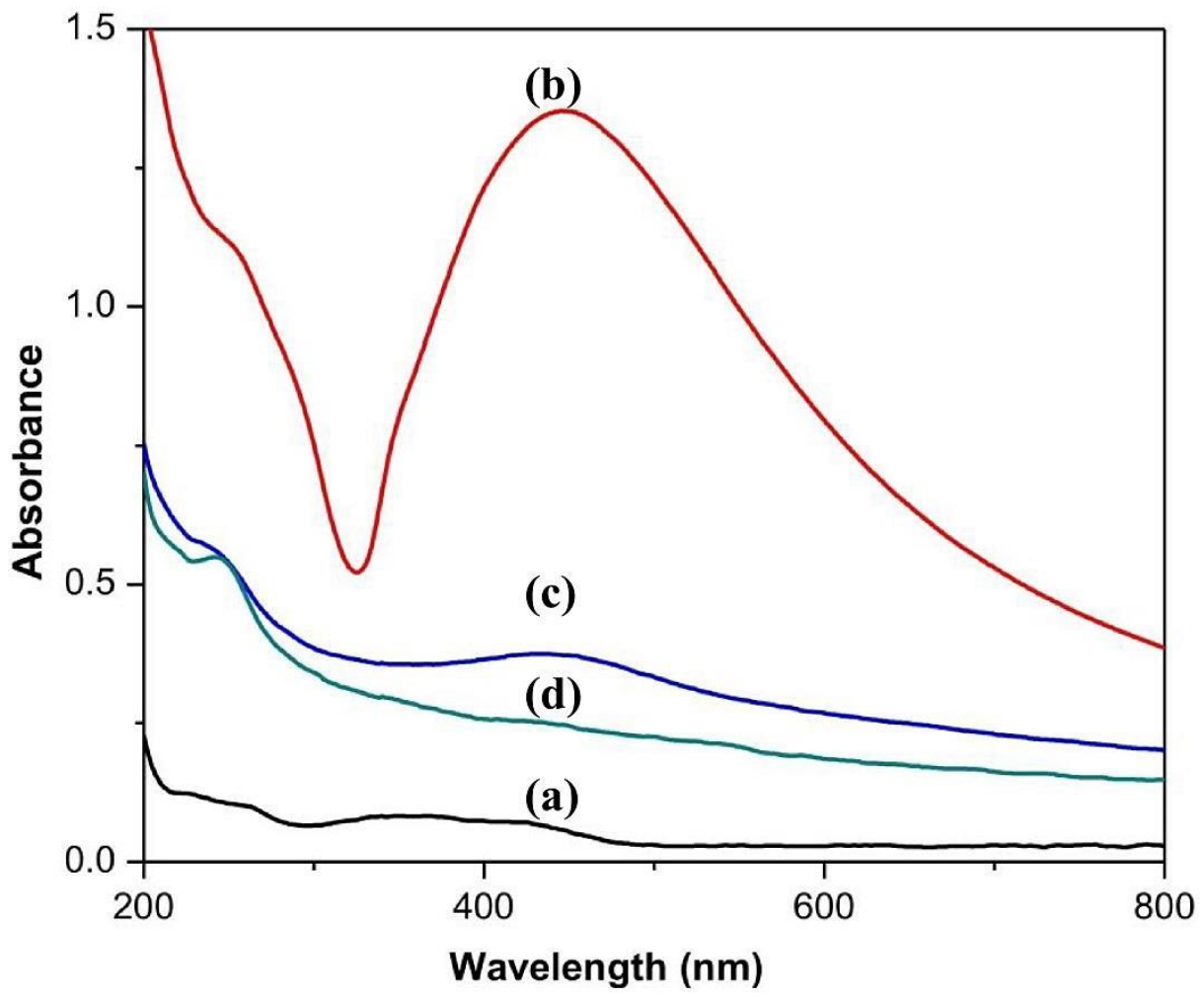


Fig. 3.

(a) Size Distribution by Intensity

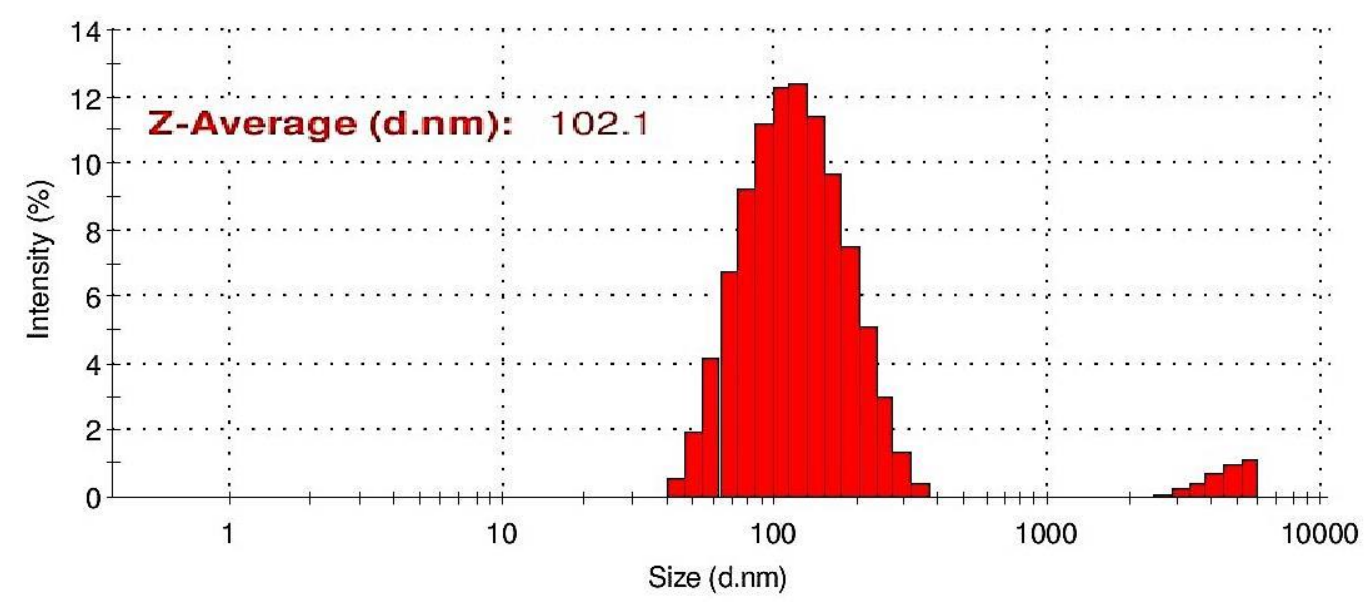

(b) Size Distribution by Intensity

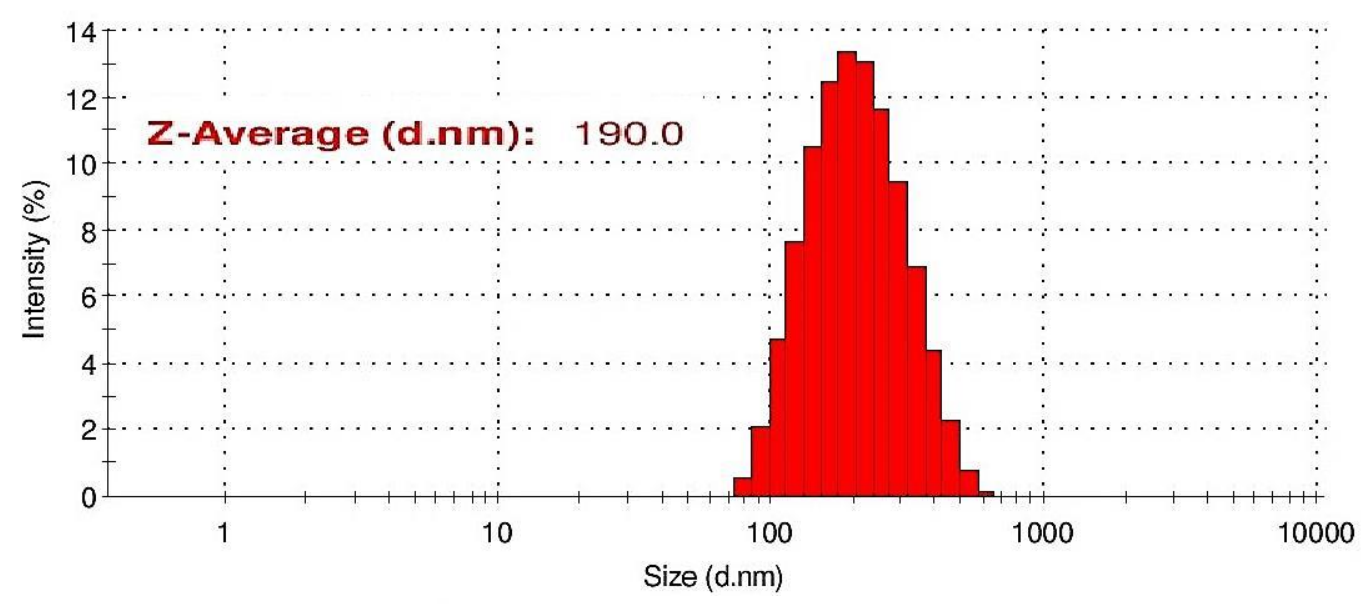

(c) Size Distribution by Intensity

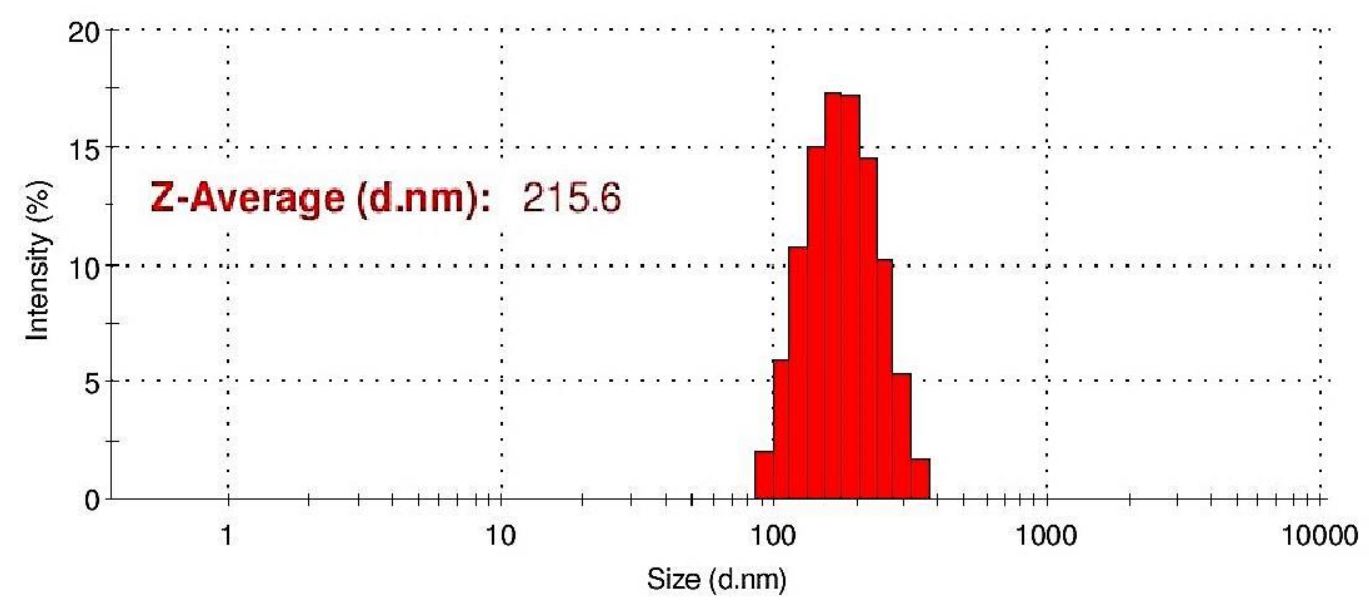


Fig. 4.

(a) Zeta Potential Distribution

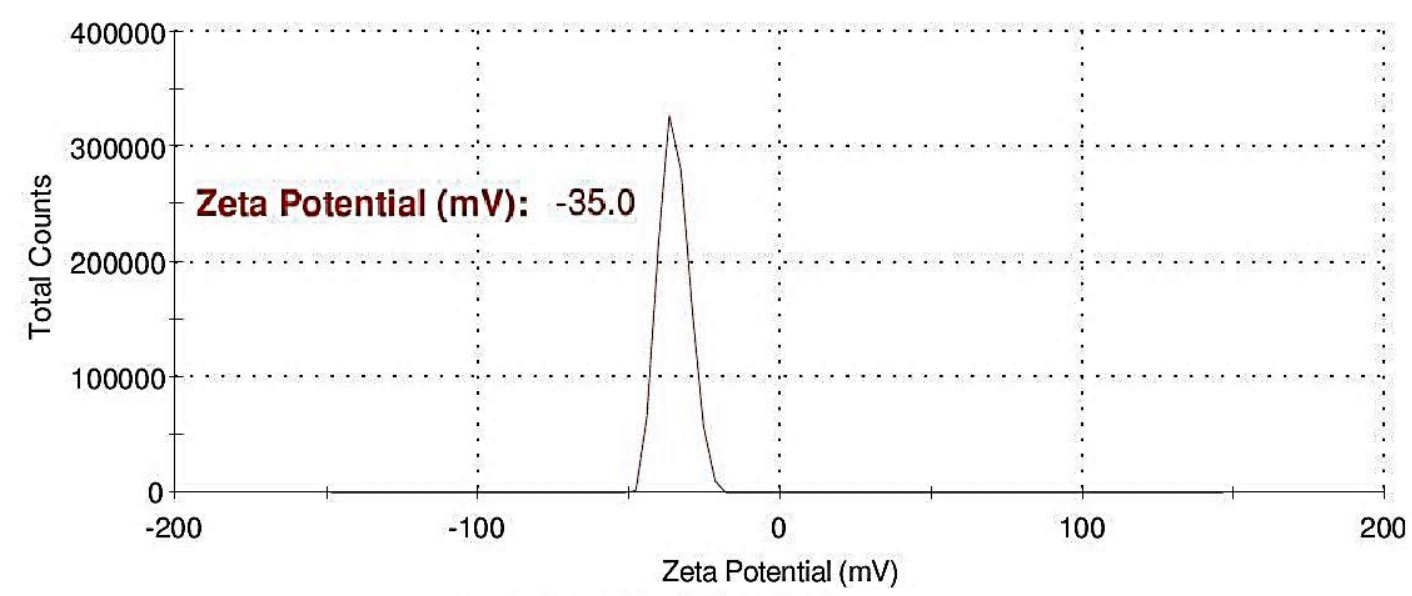

(b) Zeta Potential Distribution

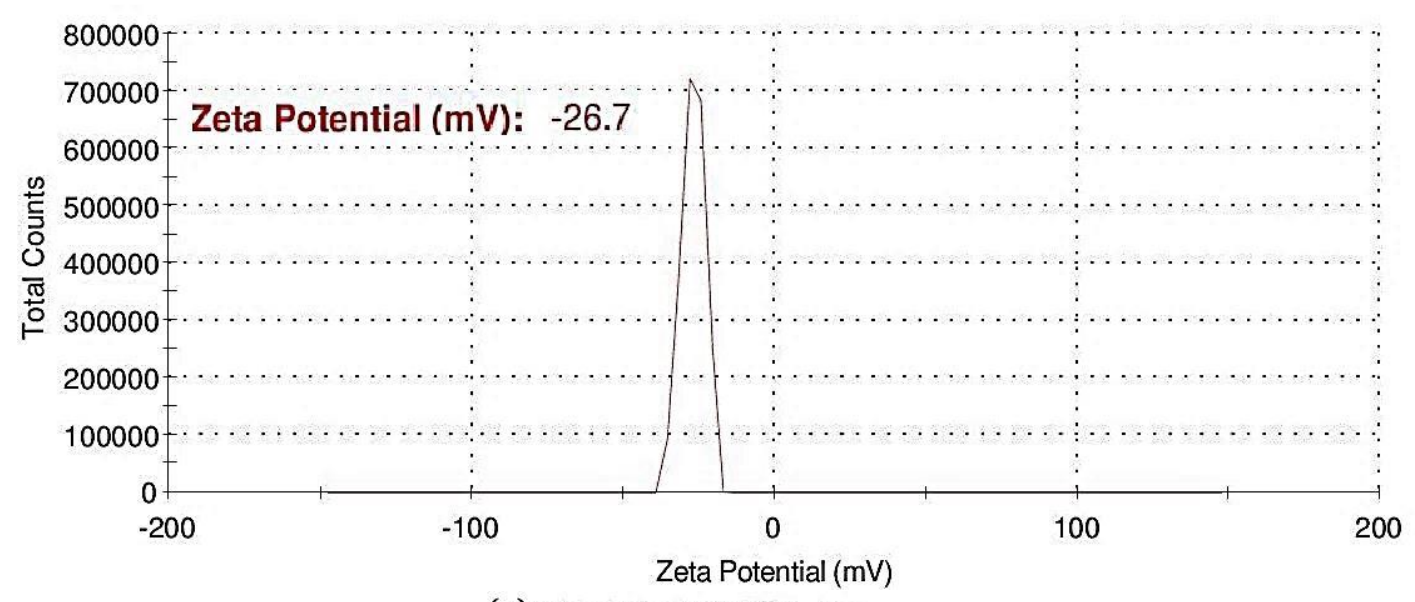

(c) Zeta Potential Distribution

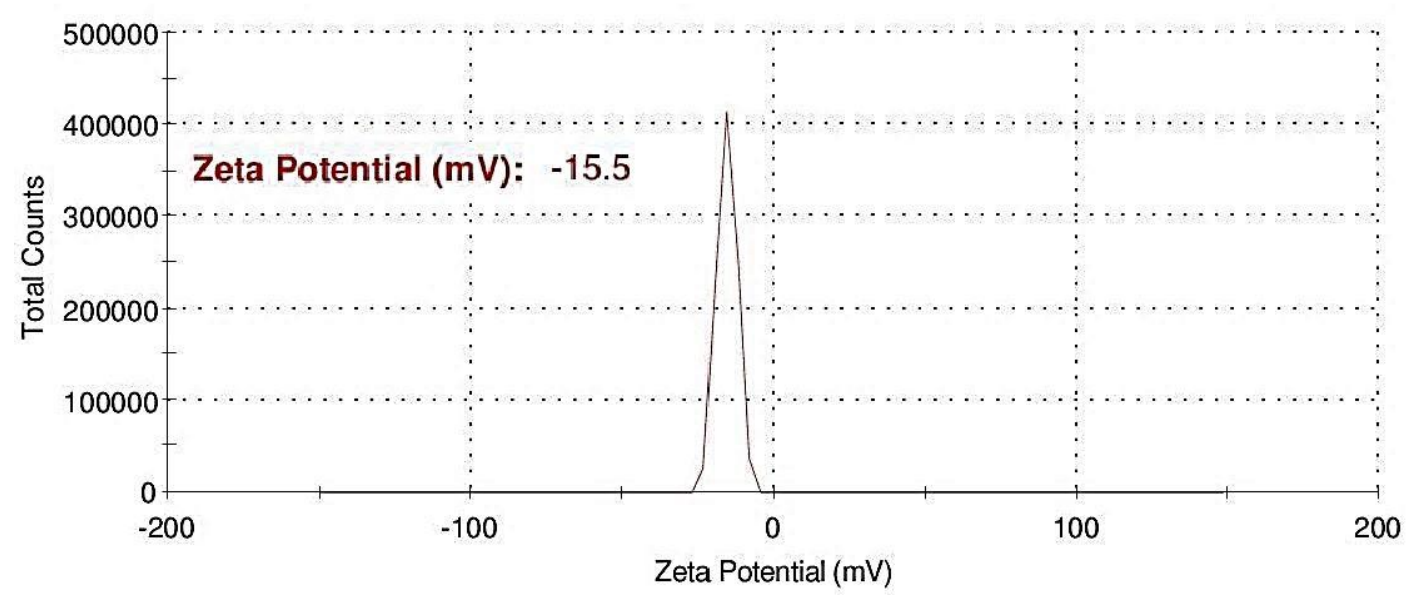


Fig. 5.

(a)

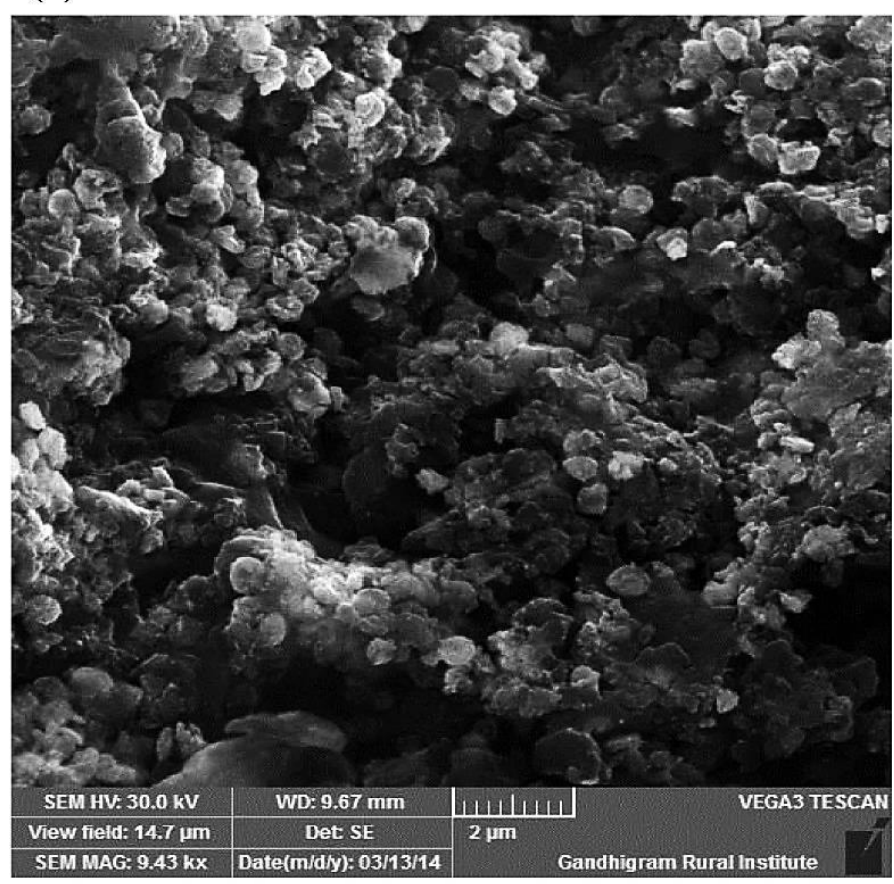

(b)

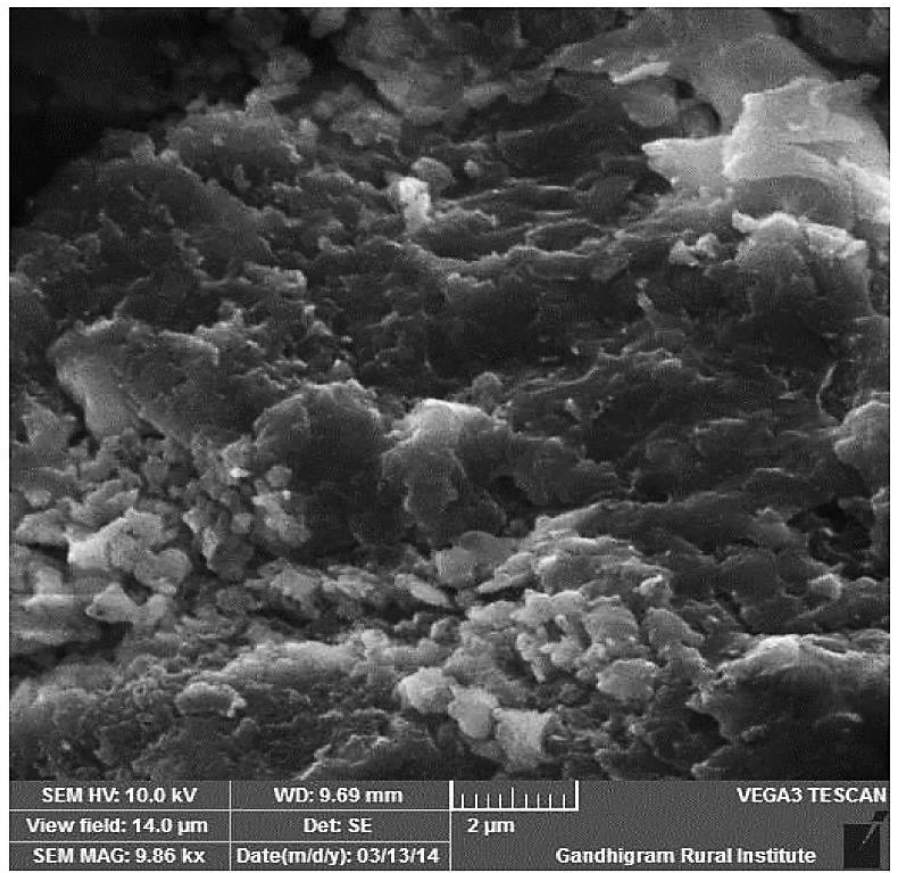

(c)

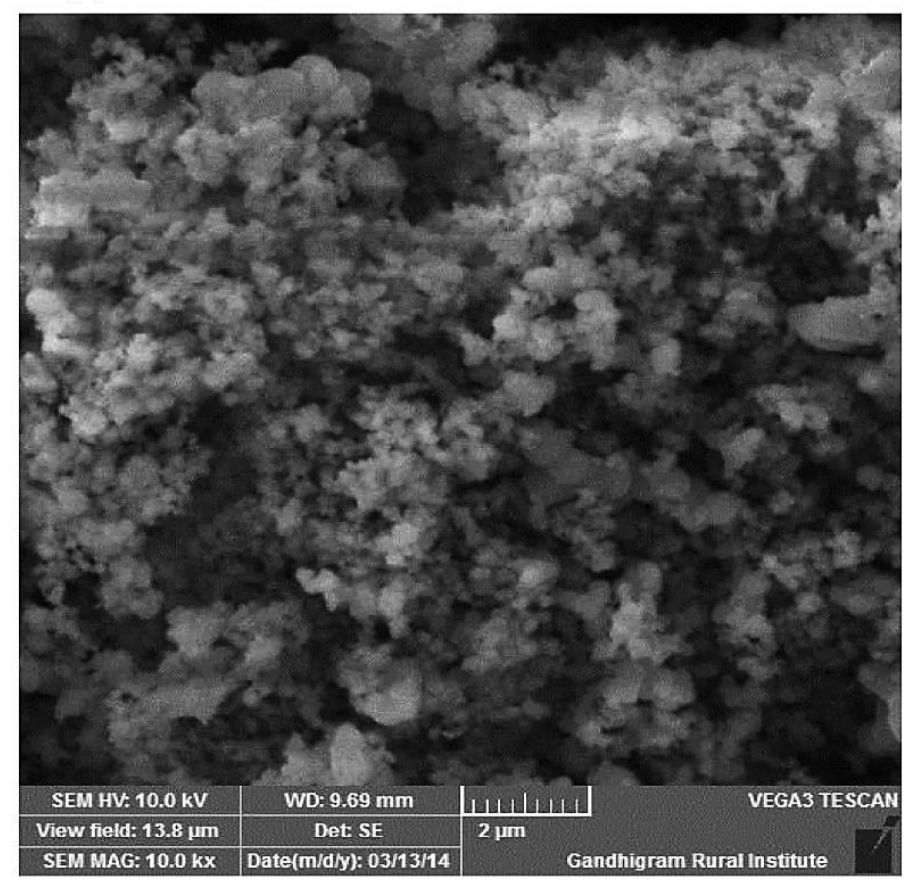


Fig. 6.

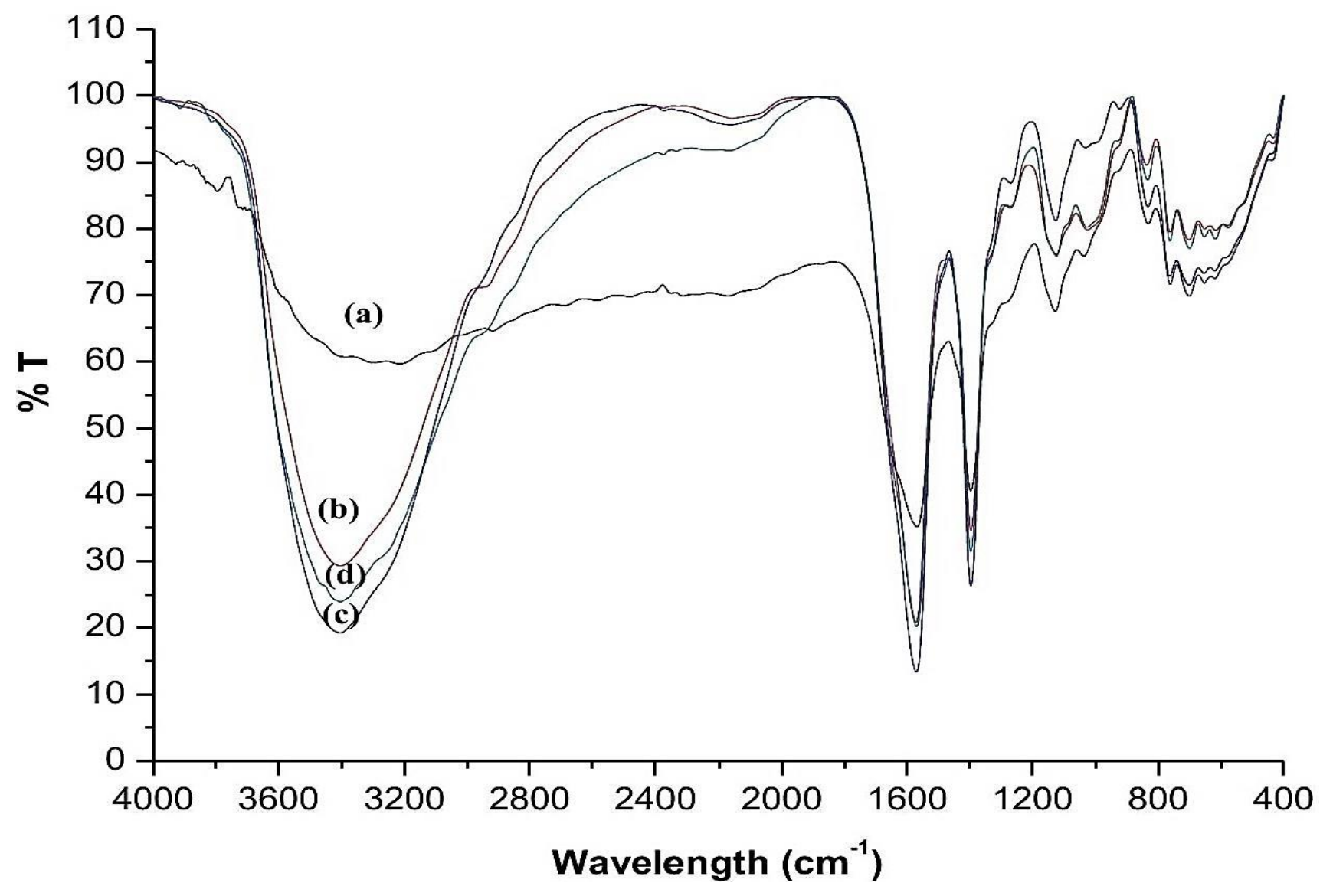


Fig. 7.
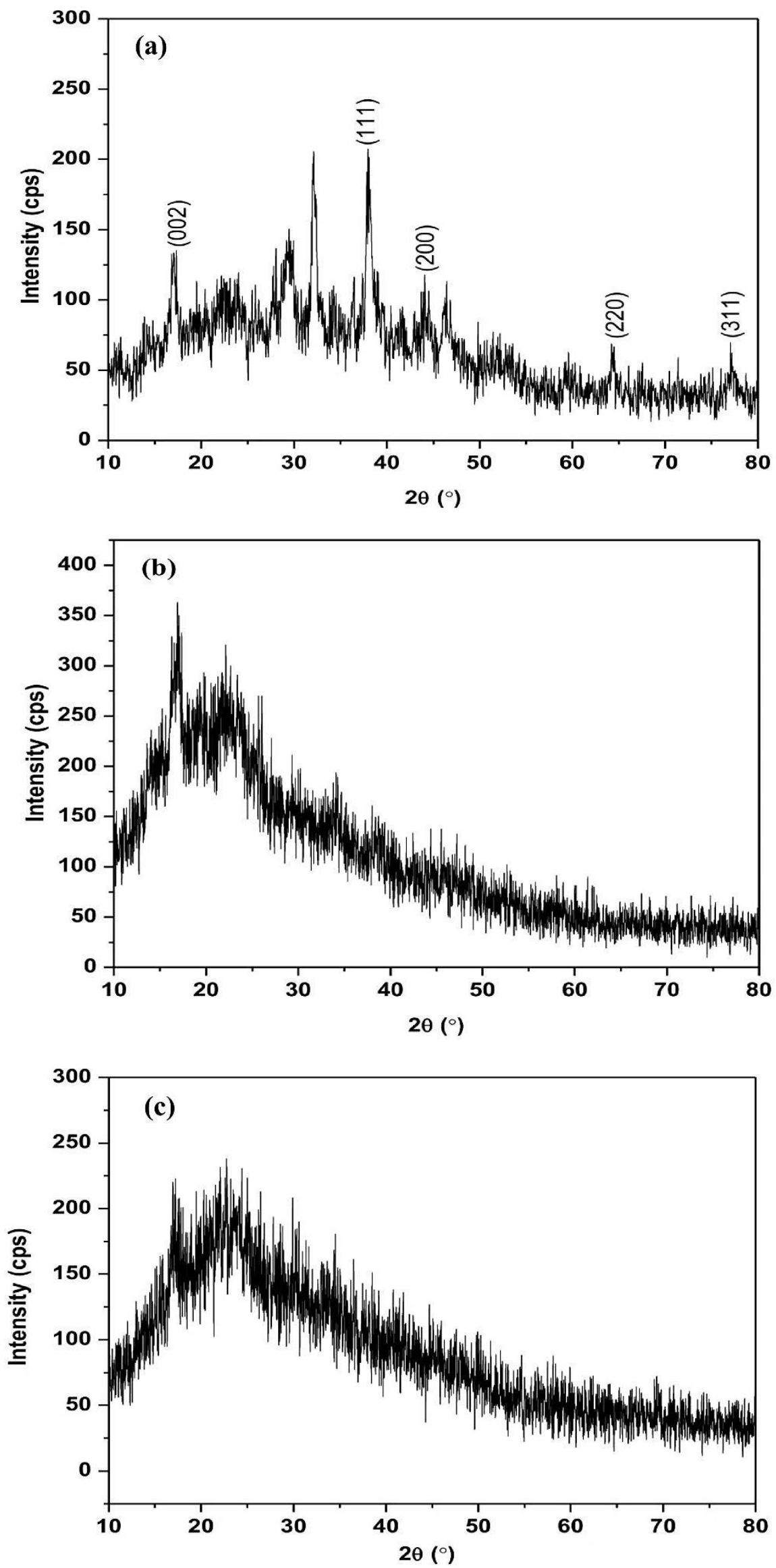
Fig. 8.
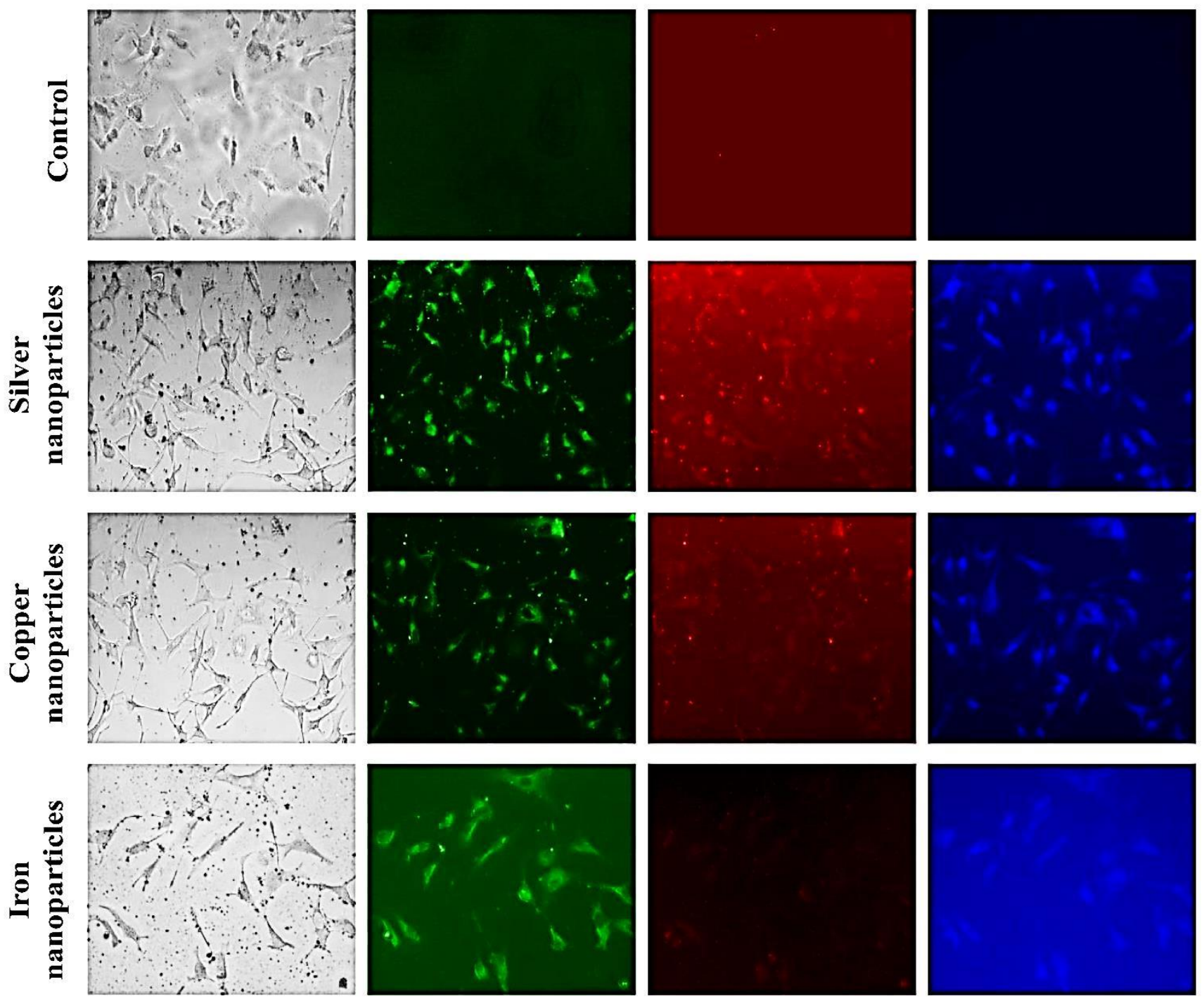


\section{Supplementary Figures}

Fig. 1.

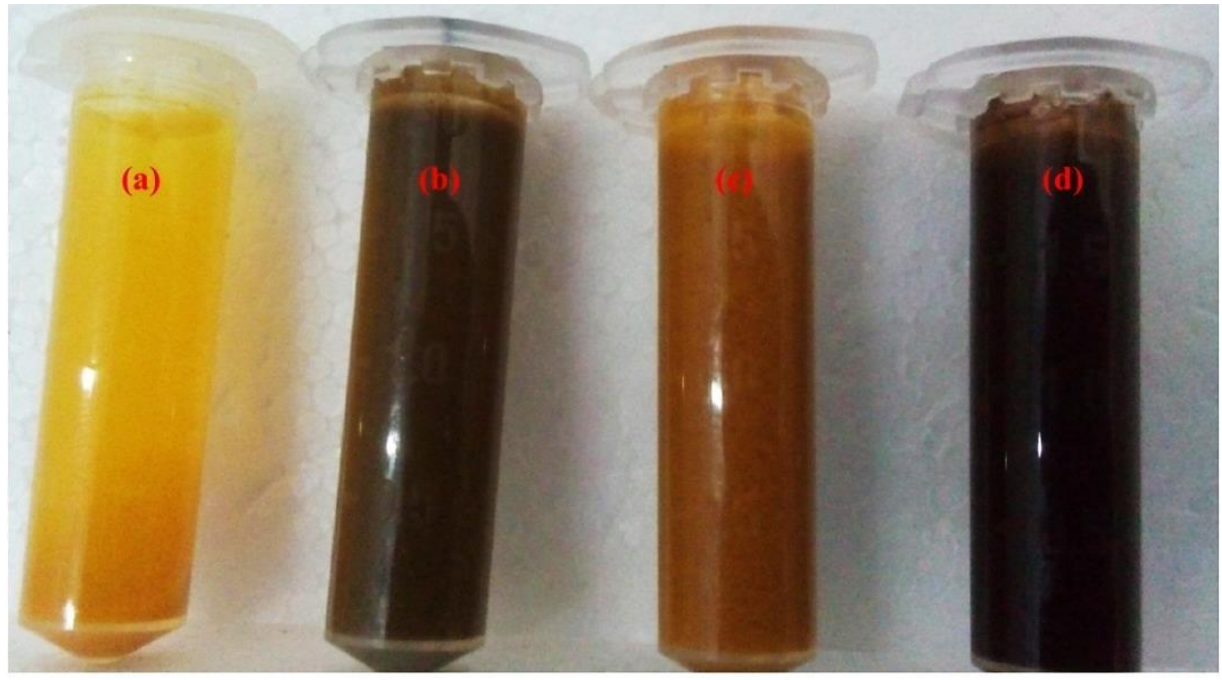


Fig. 2.

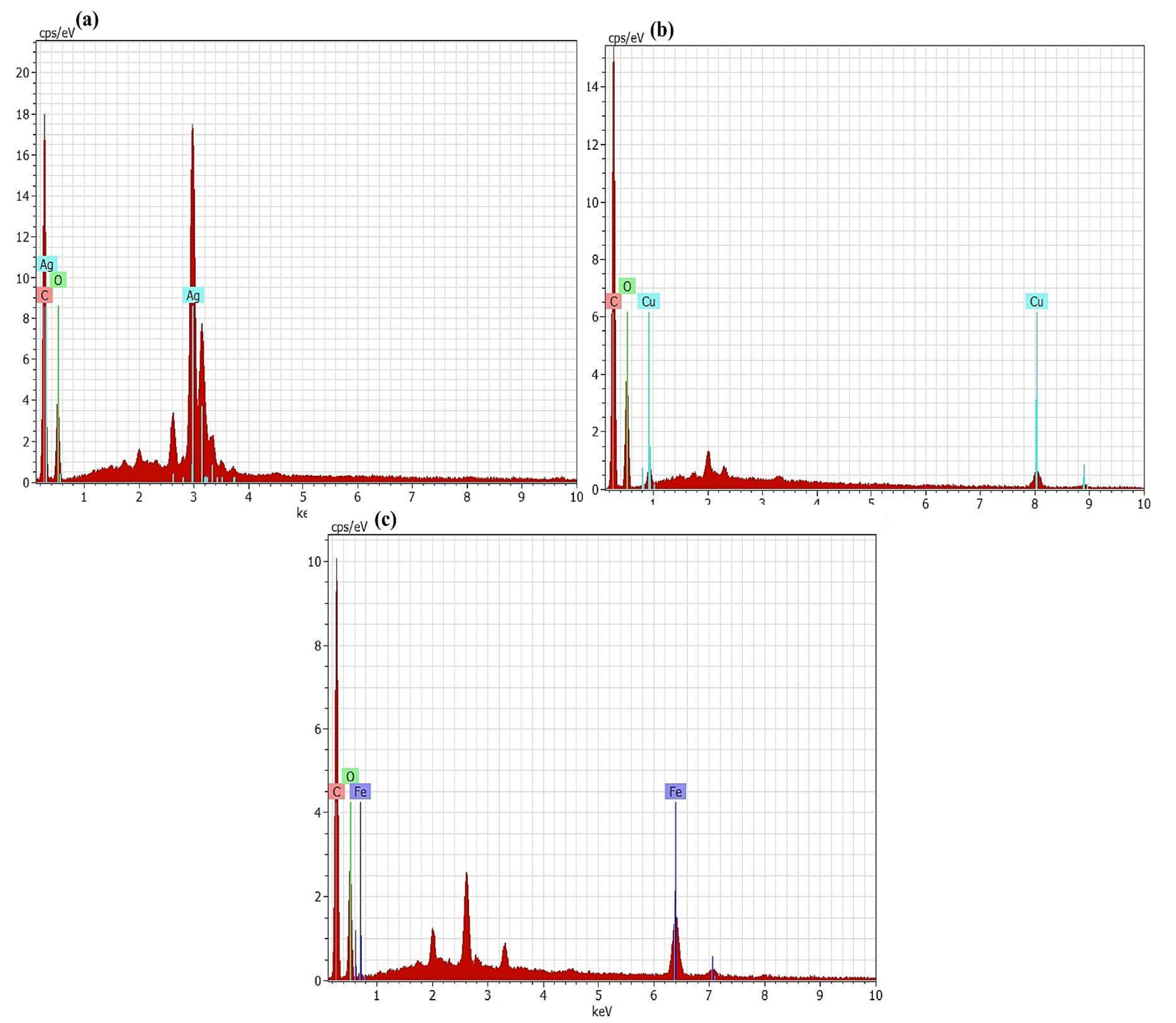


Fig. 3.

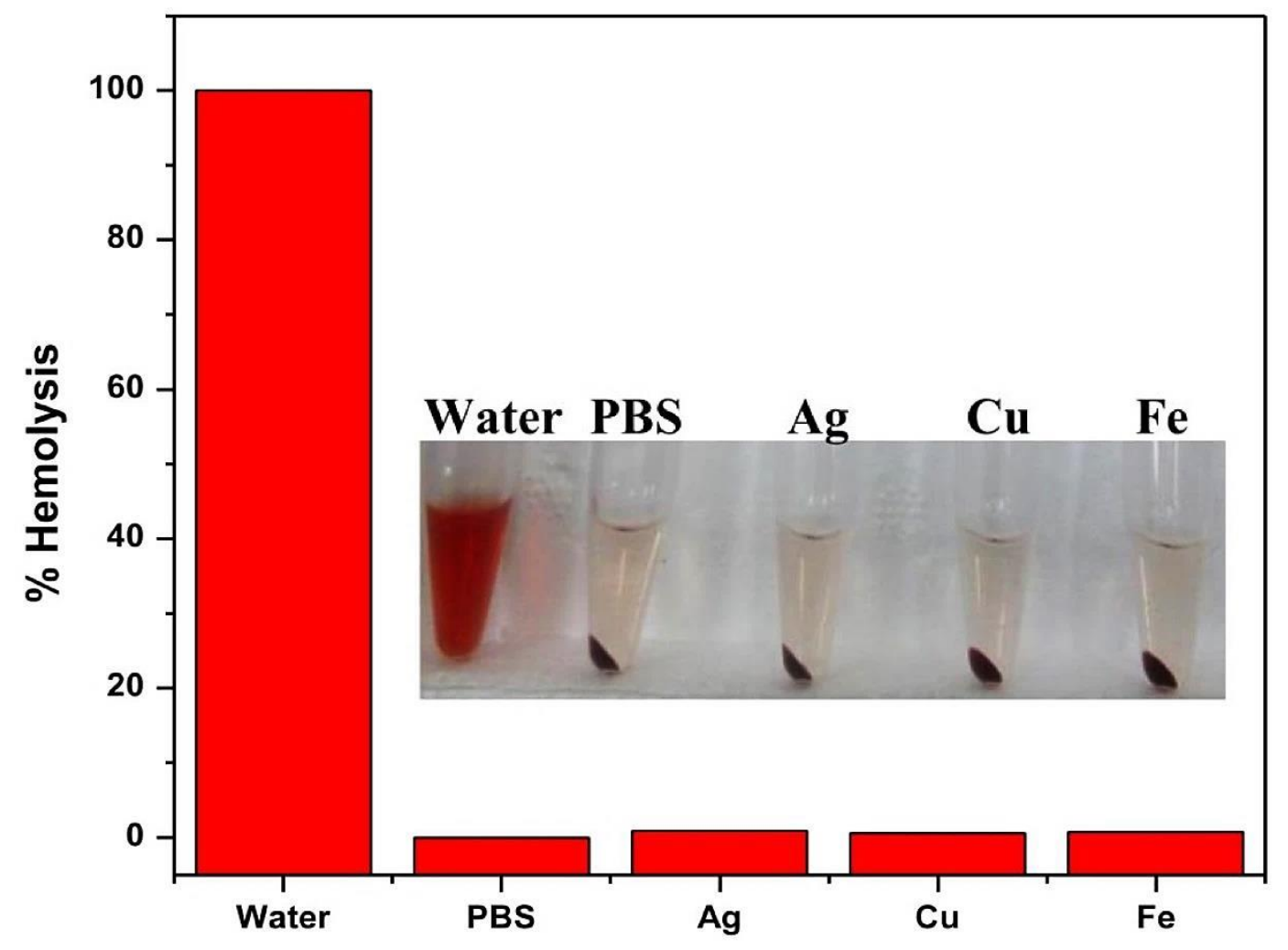


Fig. 4.

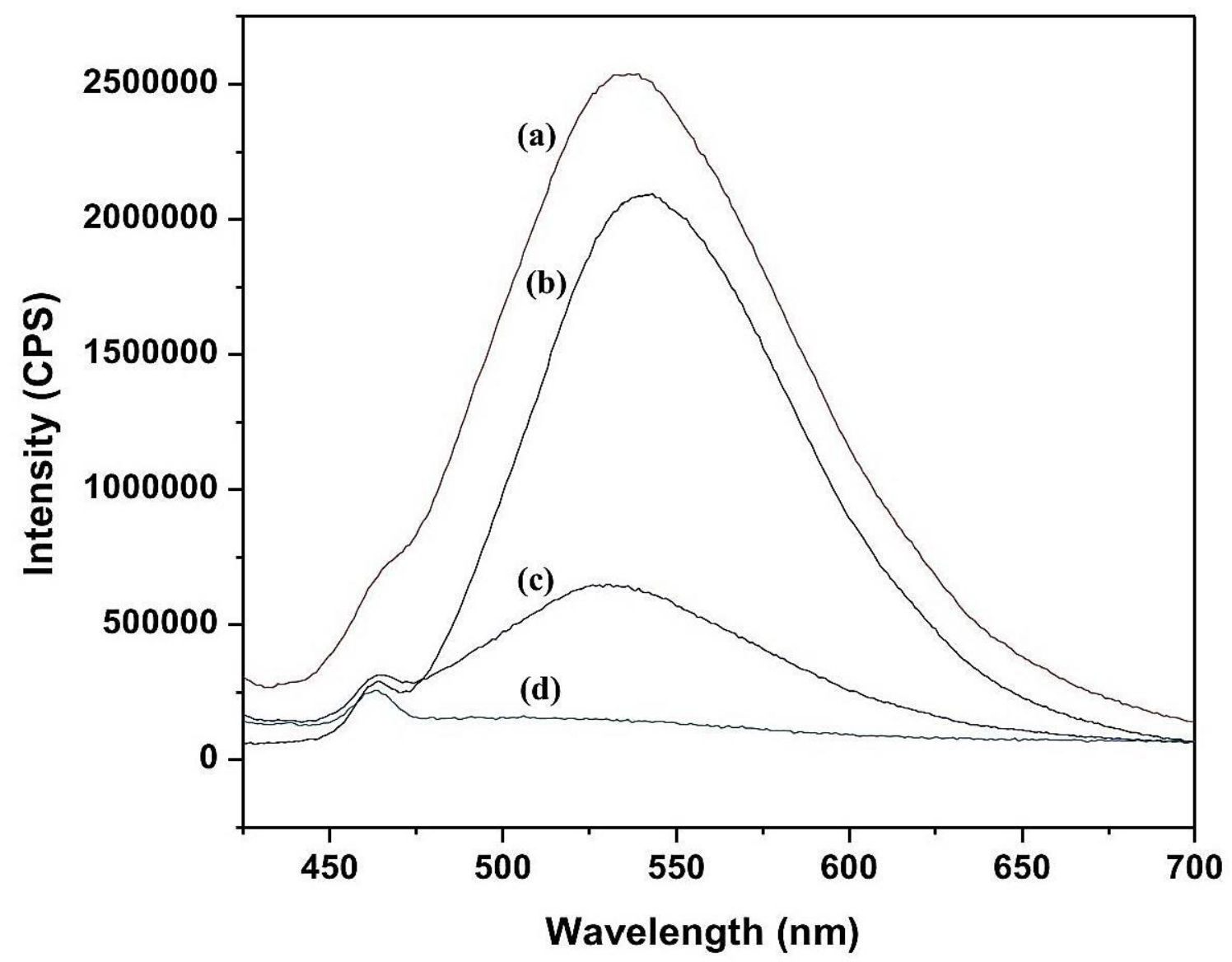

